\title{
Utilization of sludge in manufacturing Energy Efficient Bricks
}

\author{
Mary Lissy $\mathrm{P} \mathrm{N}^{1}$, Dr. M S Sreeja ${ }^{2}$ \\ ${ }^{1}$ (Department of Civil Engineering, Muthoot Institute of Technology \& Science, Varikoli, India) \\ ${ }^{2}$ (Department of Science \& Humanities, Toc H Institute of Science \& Technology, Arakkunnam, India)
}

\begin{abstract}
The bricks are obtained by moulding clay in rectangular blocks of uniform size and then by drying and burning these blocks. Burnt clay bricks have good resistance to moisture, insects and erosion and create a good room environment. They are medium in cost and have medium to high compressive strength. In brick making the major input is fuel followed by labour. Bricks manufactured from dried sludge collected from textile wastewater treatment plant were investigated. Results of tests indicated that the sludge proportion and the firing temperature were the two key factors determining the brick quality. Results showed that the brick weight loss on ignition was mainly attributed to the organic matter content in the sludge being burnt off during the firing process. With up to $6.66 \%$ sludge added to the bricks, the strength measured at temperatures $500^{\circ} \mathrm{C}$ met the requirements of the National Standards. This study showed that the pulverized sludge could be used as a brick material in reducing the firing temperature for the production of energy efficient bricks. The bonding strength can be further enhanced by controlling operating conditions.
\end{abstract}

Keywords: Energy Efficient bricks, Oven dried bricks, Casting, Recycling, Sludge.

\section{Introduction}

Rapid Industrialization and Urbanization is causing serious environmental problems. One of the major concerns amongst these is safe and sound disposal of solid wastes. There is a strong demand for environmentally safe reuse and effective disposal methods for sludge due to the increasing amount of sludge generated by the wastewater treatment plants. While sanitary landfills are commonly used for disposal or sewage sludge, rapid urbanization has made it increasingly difficult to find suitable landfill sites. Therefore, Sugar, paper pulp and Textile are three major agro based industries in India which produce large quantity of solid and liquid wastes after consuming greater amount of fresh water. Textile mills are one of the largest and oldest sectors in India. Every year textile exports generates large amount of revenues for Indian economy. The proposed method for the manufacture of energy efficient bricks using the sludge from textile industry, thus suggests a means for the waste disposal also.

\section{Literature Review}

Textile mill uses large amount of fresh water for wet operations such as Desizing, bleaching, dyeing etc. The wastewater generated from these processes is treated in effluent treatment plant by adding chemicals such as Alum, Ferric chloride, Lime and Polyelectrolyte to remove traces of cotton and dyes. During the treatment sludge gets accumulated in the primary and secondary clarifiers, which is further dried in sludge drying beds. Sludge generated in effluent treatment plants is not only troublesome to that industry but also affects the environment adversely. Many textile mills practice ultimate disposal options like Landfilling. Therefore, there is a growing need to look for various reuse options of waste materials for sustainable development. On the other hand, building construction sector consumes conventional materials such as clay, sand, gravel, cement, timber, etc which are generated directly or indirectly from natural resources. Fast growth of building construction industry is putting enormous load on the natural resources leading to environmental degradation[1]. Oven dried sludge obtained from domestic wastewater treatment plant [2] and sewage sludge ash [3] can be used as additive in building materials. Also Industrial Sludge such as Paper mill Sludge can be used in brick making-[4], for making green composite pallet making[5], in producing low cost concrete[6]. Waste lime sludge[7], Petroleum plant sludge[8] also can be used as building material. Solid waste from textile mill has the potential for use as additive in building material[1,9]. Balasubramanian[10] used up to $30 \%$ textile mill sludge in brick making with satisfactory compressive strength. As textile mill sludge contains lesser binding capacity, cement can be added as binding material in order to make hollow bricks, paving blocks, solid blocks etc. Baskar et al.[11] reported that oven dried textile mill sludge can be used as replacement to clay in manufacturing of clay bricks.

Studies revealed that at a low temperature of $100{ }^{\circ} \mathrm{C}$, any moisture remaining in the bricks is removed. The first irreversible reactions start at approximately $450-500{ }^{\circ} \mathrm{C}$, when dehydroxylation takes place. Part of the actual clay structure (the hydroxyl groups) is driven off as steam, resulting in a very small expansion of the brick. Carbonaceous organic matter (derived from plants, etc.) in the soil will burn off in the temperature range 
of $400-700{ }^{\circ} \mathrm{C}$, provided sufficient air is allowed in to convert it to carbon dioxide gas. Time is required for the brick to heat up, for oxygen to diffuse in, and for carbon dioxide to diffuse out. If this organic matter is not completely burnt off before the temperature rises to the point at which glassy material forms, the diffusion processes will not be possible, and carbon will remain within the bricks as undesirable black cores. Silica, which is a common constituent of brick making soils in the form of quartz, changes its crystal form at $573{ }^{\circ} \mathrm{C}$. This socalled inversion is accompanied by an expansion. The glass formation, which is necessary to bond particles together and make the product strong and durable, commences at approximately $900^{\circ} \mathrm{C}$, depending upon the composition of the soil used. The process, known as vitrification, involves fluxes reacting with the various other minerals in the soil to form a liquid. The cooling rate should be slow to avoid excessive thermal stresses in the bricks, particularly once the quartz inversion temperature $\left(573{ }^{\circ} \mathrm{C}\right)$ is reached, since shrinkage occurs in the presence of quartz.

\section{Materials And Methods}

Brick is one of the most common masonry units as a building material due to its properties. It has the widest range of products, with its unlimited assortment of patterns, textures and colours. Many attempts were made to incorporate wastes into the production of bricks, for examples, plaster of paris, flyash, and sludge. Recycling such wastes by incorporating them into building materials is a practical solution for pollution problem. Energy efficient bricks were made using plaster of paris (obtained from Cochin Refinery), flyash (obtained from HNL), and sludge (obtained from CSEZ, Kakkanad).

An aluminium mould of size $7.5 \times 3.3 \times 3.3 \mathrm{~cm}$ was used to cast the bricks. The mould comprises of four compartments. The raw materials used for casting of bricks were, red soil, clay, fine sand and waste materials (fly ash and sludge). The sludge used for casting of bricks were collected from CSEZ, Kakkanad. The sludge contains ferric chloride, lime, cowdung and textile wastes which was obtained from waste water treatment plant.

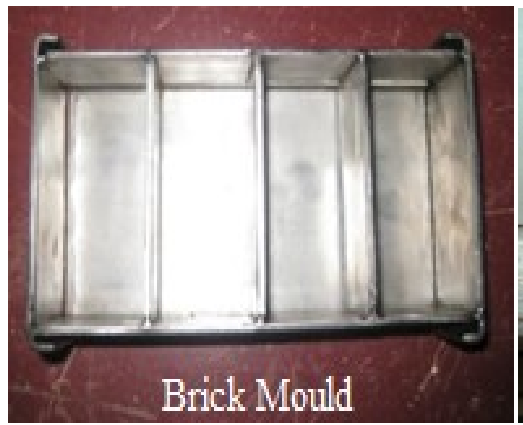

Fig.1 Aluminium Mould

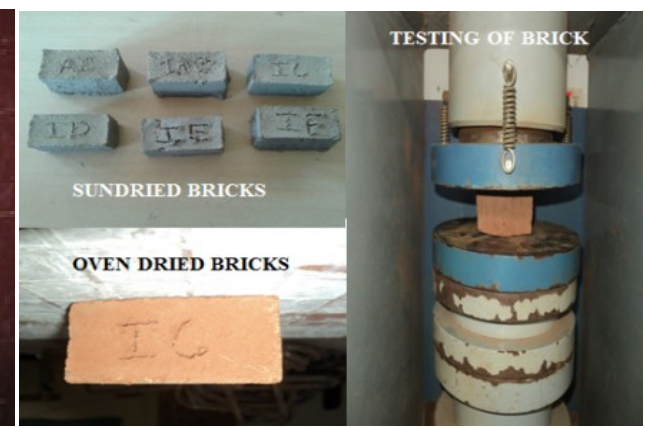

Fig.2 Drying \& Testing of bricks

The bricks were casted by the soft mud method. The raw materials, red soil, clay, fine sand and waste materials were collected in a tray in the required amounts. They were mixed, as per the given proportion. Clay was mixed with water to form the finished product. The amount of water to be added depends on the nature of the clays and their plasticity. This water is removed during drying and firing. The mix is placed in the aluminium mould to form the size unit desired. To keep the clay from sticking, the moulds were lubricated with grease; after they are filled, excess clay is struck from the top of the mould. After the bricks are formed, they were sun dried to remove the free water. Bricks were fired and cooled in a muffle furnace, an oven-type chamber at temperatures of $400{ }^{\circ} \mathrm{C}, 500{ }^{\circ} \mathrm{C}$ and $600{ }^{\circ} \mathrm{C}$.

\section{Results And Discussions}

Six bricks of size $7.5 \times 3.3 \times 3.3 \mathrm{~cm}$ were casted using sludge. $1250 \mathrm{~g}$ of red soil, $100 \mathrm{~g}$ of clay, $150 \mathrm{~g}$ of sludge and $750 \mathrm{~g}$ of fine sand were used as the raw materials for casting. $850 \mathrm{ml}$ of water was added. Bricks were heated to a temperature of $500^{\circ} \mathrm{C}$. 


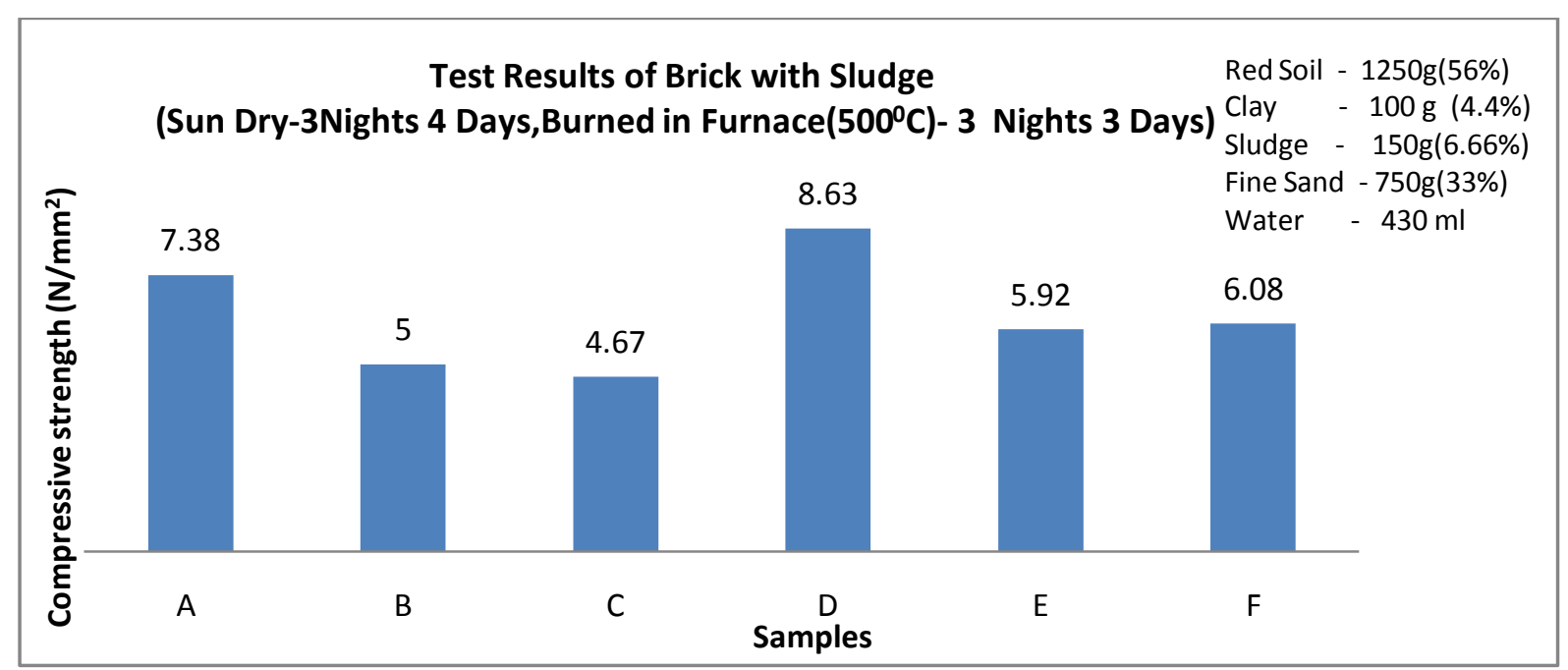

Fig.3 Test Results of Brick with Sludge

Eight numbers of normal bricks of size $7.5 \times 3.3 \times 3.3 \mathrm{~cm}$ were casted to compare the compressive strength of bricks casted using sludge. $1250 \mathrm{~g}$ of red soil, $250 \mathrm{~g}$ of clay and $750 \mathrm{~g}$ of fine sand were used as the raw materials for casting normal bricks. $780 \mathrm{ml}$ of water was added. All the bricks were heated to $500^{\circ} \mathrm{C}$.

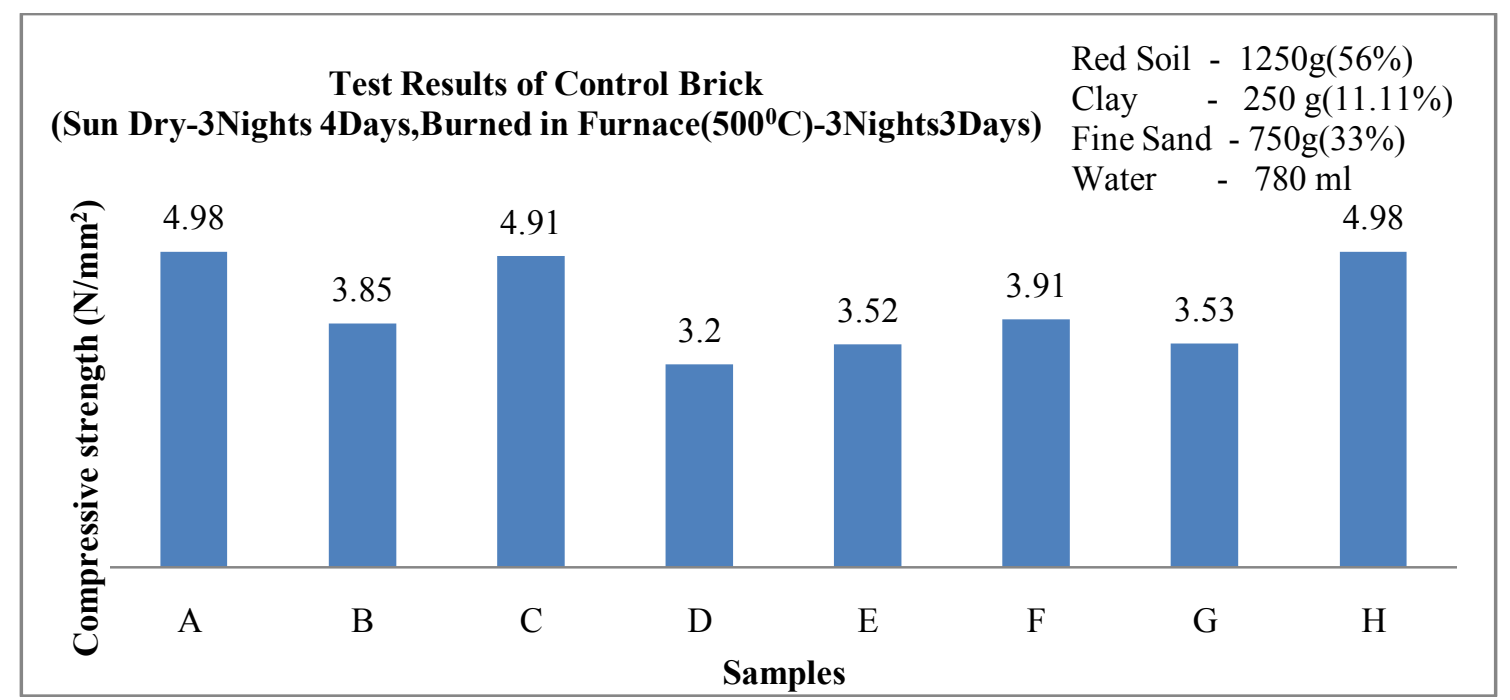

Fig.4 Test Results of Control brick

The bricks casted using sludge as a waste material showed high compressive strength than control bricks. The bricks were kept for sundry for three nights and four days. It was burnt to a temperature of $500^{\circ} \mathrm{C}$ in muffle furnace for three days and three nights. The control bricks and sludge bricks were casted with same condition for comparison.

Increasing the sludge proportion and temperature resulted in increase in brick weight loss on ignition. The weight loss criterion for a normal clay brick is $15 \%$. Visual observation showed that an uneven surface was found for the sludge-brick. It is speculated that the formation of this unwanted surface was mainly due to the organic component burnt off during the firing process. For a normal clay brick, the loss of weight after firing at $800{ }^{\circ} \mathrm{C}$ is mainly attributed to the organic matter content in clay. However, upon the addition of sludge in the mixture, the loss of weight apparently increased because the contribution of organic matter loss from sludge. Furthermore the brick weight loss on ignition also depends on the inorganic substances in both clay and sludge being burnt off during the firing process.

\section{Conclusion}

The most energy efficient bricks were casted using sludge as raw materials at a temperature of $500^{\circ} \mathrm{C}$. By casting bricks with different raw materials, sludge bricks showed the maximum compressive 
strength when compared to control bricks. The sludge bricks were kept for sundry for three nights and four days. It was burnt to a temperature of $500{ }^{\circ} \mathrm{C}$ in muffle furnace for three days and three nights. The control bricks and sludge bricks were casted with same condition for comparison. Since the test results showed more than the minimum compressive strength of an ordinary brick, it can be concluded that energy efficient bricks made of sludge can be used for construction purposes due to its good strength. The bricks casted with less number of days of burning at low temperature can be used instead of ordinary bricks in construction at a faster rate.

\section{Acknowledgements}

Motivation and advice were given by Prof. Dr V Job .Kuruvilla, Director, TIST. The experimental studies of the energy efficient bricks were conducted in the Department of Civil Engineering at Toc $\mathrm{H}$ Institute of Science and Technology (TIST),Arakkunnam.

\section{References}

[1] A. Pappu, M. Saxena, S. R. Asolekar. "Solid waste generation in India and their recycling potential in building material". Journal of Building and Environment. Vol. - 42, pp. 2311-2320, 2007.

[2] J. Alleman, N. Berman. "Constructive sludge management: Biobrick". ASCE J Environ Eng. Vol. - 110(2), pp. 301-311, 1984.

[3] N. Okuno, S. Takahashi. "Full scale application of manufacturing of bricks from sewage”.J Water Sci Technol. Vol. - 36(11), pp. 243-250, 1997.

[4] D. Jegatheeswaran, R. Malathy. "Utilization of paper mill sludge in manufacturing of bricks - An environmental friendly approach". Poll Res, Vol.- 30(3), pp. 299-303, 2011.

[5] S. Kim, H. J. Kim and J. C. Park. "Application of recycled paper sludge and biomass materials in manufacture of green composite pallet”.Resources, Conservation and Recycling. Vol. - 53: pp.674-679, 2009.

[6] R. Srinivasan, K. Sathiya, M. Palanisamy. "Experimental investigation in developing low cost concrete from paper industry sludge”.BuletinulInstitutuluiPolitechnic Din IASI, Vol. -LX (1), pp. 43-56, 2010.

[7] M. Singh, M. Garg. "Utilization of waste lime sludge as building material". J Sci and Indu strial Res. Vol. - 67: pp. 161 - 166, 2008.

[8] P. Sengupta, N. Saikia and P. C. Borthakur. "Bricks from petroleum effluent treatment plant sludge: Properties and environmental characteristics". J Environ Eng. ASCE; Vol. - 128(11), pp. 1090 - 1099, 2002.

[9] K. Senthilkumar, V. Sivakumar and P. Akilamudhan. "Experimental studies on disposal of various industrial solid wastes". J Mod Appl Sci. Vol. - 2(6): pp. 128-132, 2008.

[10] J. Balasubramanian, P. Sabumon, J. Lazar and R. Ilangovan. "Reuse of textile effluent treatment plant sludge in building materials". J Waste Manage.Vol. - 26: pp. 22-28, 2006. International Journal of Environmental Protection May. 2013, Vol. 3 Iss. 5, PP. 6-13

[11] R. Baskar, K. Begum and S. Sundaram. "Characterization and reuse of textile effluent treatment plant waste sludge in clay bricks". Journal of University of Chemical and metallurgy. Vol. - 41(4): pp. 473-478, 2006. 